\title{
"Papel, penas e drogas para tinta": materiais de escritório na administração diamantina do século XVIII
}

\author{
"Paper, quills and drugs for ink": office supplies in the diamonds administration \\ in the 18th century
}

\section{RÉGIS CLEMENTE QUINTÃO'}

https://orcid.org/0000-000 1-8507-4671

Universidade Federal de Minas Gerais / Belo Horizonte, MG, Brasil

RESUMO: Este artigo aborda a importação, a circulação e o uso de materiais de escritório pela Real Extração dos Diamantes, em Minas Gerais, no último quartel do século XVIII, indagando sobre sua importância para a administração e o controle fiscal pretendidos pelas autoridades do período. A partir de fontes pertencentes ao fundo Erário Régio do Arquivo Histórico do Tribunal de Contas de Portugal, desvelamos o expediente daquela instituição e o consumo de livros contábeis, papéis de diversas qualidades e fabricantes europeus, penas de escrever e substâncias utilizadas na confecção da tinta ferrogálica. $\bigcirc$ estudo desses elementos evidencia não apenas sua relevância para as atividades burocráticas daquela sociedade, mas também uma dimensão material que estamos pouco acostumados a enxergar no passado. Afinal, conhecer esses insumos e artefatos possibilita a compreensão de algumas condições de produção dos documentos preservados nos arquivos e bibliotecas.

PALAVRAS-CHAVE: Material de escritório. Papéis. Importação. Real Extração. Minas Gerais.

ABSTRACT: This article discusses the import, circulation and use of office supplies by the Royal Diamond Extraction in Minas Gerais during the last decades of the 18th century, questioning about their importance for the administration and fiscal control intended by the authorities of that period. Utilizing sources belonging to the Real Erário fund from the Historical

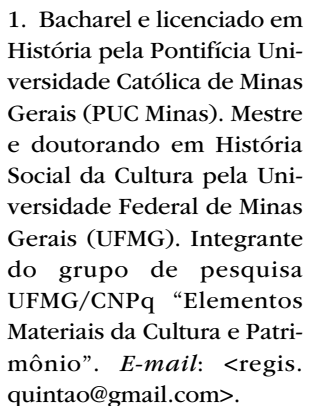

quintao@gmail.com>. 
Archives of the Portuguese Court of Auditors, we unveiled the work of that institution and the consumption of account books, papers of varying quality and European manufacturers, quill pens and substances used in the production of iron gall ink. The study of those elements evinces not only their relevance to the bureaucratic activities of that society, but also a material dimension that we rarely see in the past. After all, such supplies and artifacts allow to understand some production conditions of documents preserved in archives and libraries.

KEYWORDS: Office supplies. Papers. Import. Royal Extraction. Minas Gerais. 
Em 1771, sob a governação de d. José l e do marquês de Pombal, foi criada a Real Extração dos Diamantes. Com o mais novo monopólio da Coroa portuguesa, pretendia-se controlar diretamente a produção diamantífera, estabelecendo um sistema cuja finalidade principal era aumentar as rendas reais, tentando, por outro lado, minimizar seus custos, além de combater fraudes, contrabandos e corrupção. Essa administração teve início em $1^{\circ}$ de janeiro de 1772 e funcionou até meados do século XIX. Contava com duas sedes: em Lisboa havia a Diretoria Geral da Real Extração dos Diamantes das Minas do Brasil e, na capitania de Minas Gerais, vinculada à referida Diretoria, estava a Junta da Administração Diamantina, situada no Arraial do Tejuco, na comarca do Serro do Frio.

Nesse contexto de reorganização financeira levada a cabo pelas reformas pombalinas, houve a produção de considerável massa documental, decorrente da constante e obrigatória correspondência entre referidas instâncias da administração dos diamantes, bem como dos registros fazendários nos livros de receitas e despesas. Assim, apenas referentes à Real Extração, instituição privilegiada neste artigo, constam no fundo Erário Régio do Arquivo Histórico do Tribunal de Contas de Portugal onze códices de 1771 a 1805 exclusivamente sobre assuntos relativos à exploração das pedras preciosas. ${ }^{2}$ A maior parte dessas fontes documentais permanece inédita e ainda não pesquisada. São inúmeras as possibilidades de investigação a partir do acervo em pauta. No entanto, nosso objetivo é indagar sobre algumas condições e processos de confecção de todo esse volume de manuscritos. Em outras palavras, quais recursos eram necessários para o registro das informações textuais pela Real Extração dos Diamantes?

Não se trata apenas de identificar e descrever os materiais, mas também de tentar interpretar a realidade social da qual fizeram parte. ${ }^{3}$ Nossa intenção, portanto, é explicitar seu uso, suas possibilidades e seus sentidos naquele contexto, privilegiando a dimensão da escrita administrativa e destacando sua importância como parte das relações humanas, e não somente como resultado delas. Nessa perspectiva, para Marcelo Rede, "as coisas são dotadas de animação, também elas exercem força motriz, também elas atuam socialmente, conformando um quadro de referências, possibilidades e limites ao agente humano, independente de este ter consciência disso ou não". ${ }^{4}$ Assim, é possível afirmar que sem os materiais e insumos utilizados pela Real Extração, à frente listados, toda essa documentação indicada sequer teria existido.

Do mesmo modo, para aquela sociedade, sem esses materiais de escritório seria impossível administrar o próprio monopólio diamantino, dependente destes para a eficácia da gestão e do controle da rotina contábil. A partir deles podemos compreender aspectos variados da organização burocrática pretendida pelas
2. Todas as fontes manuscritas citadas neste artigo estão disponíveis no livro de Boschi e Quintão (2019).

3. Cf. Meneses (2011).

4. Rede (2012, p. 145) 
5. Meneses; Borrego (2018,

p. 3).

6. Cf. Miller (2013).

7. Ibid., p. 78

8. Ibid., p. 79 .

9. Cf. Almada (2018). autoridades portuguesas do período. Em última instância, não só esses como outros "elementos materiais da cultura são documentos primordiais para o conhecimento histórico, e saber mobilizá-los favorece compreensões complexas de um passado que não passa por completo, um passado igualmente durável". ${ }^{5}$ É correto, então, considerar que os materiais utilizados pela administração diamantina não são apenas testemunhos daquele contexto, nem são somente resultados das preocupações fazendárias: eles são a própria organização administrativa e fiscal à qual nos referimos. Assim, é quase impossível separar as ideias e os objetos, na medida em que eles permanecem juntos, como uma só coisa. Não são meramente representações do passado, mas também vestígios de uma realidade que perdura ao longo do tempo nas estantes dos arquivos e das bibliotecas.

Dessa forma, desvelar aspectos ainda pouco conhecidos da aquisição, da circulação e do consumo de materiais de escritório, tal como eram chamados à época, não é uma trivialidade. Estudá-los pode se revelar como uma profícua abordagem do passado. Aliás, como defende Daniel Miller, os "trecos, troços e coisas" que os homens criam, consomem e usam estão longe de se constituírem como superficialidade de determinada realidade. ${ }^{\dagger}$ Eles são parte de um mesmo processo. Para o referido autor, as coisas dizem respeito à própria sociedade na qual circulam e são indissociáveis desta. Nesse sentido, podemos depreender que para a antropologia, assim como para a história, "os objetos são importantes não porque sejam evidentes e fisicamente restrinjam ou habilitem, mas justo o contrário. Muitas vezes, é precisamente porque nós não os vemos".? Qual pesquisador, ao ler ou transcrever uma fonte da época moderna, se pergunta quais materiais foram precisos para o registro daquelas palavras? Que tipo de papel foi utilizado? Qual a sua origem? Como a tinta era composta e preparada? Não seria exagero afirmar que todos esses insumos, tomando emprestadas as palavras de Miller, tornam-se coisas "invisíveis e não mencionadas, condição que em geral alcançam por serem familiares e tidas como dadas". ${ }^{8}$ De fato, os elementos materiais da escrita administrativa raramente despertam a atenção dos estudiosos.

É preciso esclarecer que nossa proposta não é uma análise material propriamente dita, pois partimos dos indícios encontrados nos documentos escritos, e não da fonte material como objeto de investigação em si. A esse respeito, como destaca Márcia Almada, a análise da materialidade requer minuciosa avaliação das propriedades formais e físicas do objeto ou mesmo do documento manuscrito, também considerado um artefato pela autora. ${ }^{9}$ Para tanto, são necessários recursos fundamentais, como luzes especiais, microscópio digital, entre outros, a fim de definir marcas, estampas, a aplicação de tintas, técnicas, sobreposições etc. Em suma, para a autora, "o objetivo de uma análise visual e material com instrumentos básicos de 
exame e iluminação de diversos tipos é a determinação dos materiais originais e a história do objeto evidenciada em suas condições físicas atuais". ${ }^{10}$ Ainda segundo Almada, a interdisciplinaridade obrigatoriamente se impõe nesse tipo de abordagem, comumente combinando aportes teórico-metodológicos da codicologia, da bibliografia material, da diplomática, da paleografia e, claro, da história. ${ }^{.1}$

Especificamente sobre a circulação de papel, o campo de estudo da codicologia tem produzido importantes constatações. Trabalhos de especialistas em áreas como a linguagem têm destacado alguns processos da produção papeleira europeia e sua difusão no Brasil nos séculos XVIII e XIX, como atesta, por exemplo, a pesquisa de George Gleyk Max de Oliveira para a região do Mato Grosso. ${ }^{12}$ Outro caminho possível diz respeito ao protocolo Improved Damage Assessment of Parchment (ldap), cujo propósito é indicar possibilidades e mecanismos de identificação macroscópica do estado de conservação e microscópica da deterioração, bem como para detectar danos nesse tipo de suporte. De acordo com Marina Furtado Gonçalves, como não há um método específico para seu exame, a partir de tal protocolo:

desenvolveu-se uma sequência de procedimentos para o estudo material de documentos em papel, resultando em uma coleção de dados qualitativos sobre aspectos inerentes à deterioração do suporte, auxiliando que a leitura do dano seja relacionada com os textos, os usos e a produção do objeto..$^{13}$

A partir de tal metodologia, ao analisar parte do acervo da Coleção Casa dos Contos, pertencente ao Arquivo Público Mineiro, a autora destaca que é necessário ultrapassar a centralidade do conteúdo do documento, evidenciando outros aspectos da estrutura material dos suportes, seus métodos de produção e seus fabricantes europeus. ${ }^{14}$ De modo geral, porém, as informações escritas continuam sendo fundamentais nesse campo do conhecimento, uma vez que por meio delas, e com auxílio da paleografia, é possível identificar vários aspectos complementares à analise material, como os insumos e instrumentos utilizados no cotidiano da administração colonial.

Como dito, embora não tenhamos o artefato físico como ponto de partida analítico, mas os registros textuais que dão conta da sua existência, esta primeira incursão sobre o tema acena para importantes achados a respeito da circulação, entre os dois lados do Atlântico, de papel e outros materiais utilizados no trabalho administrativo. De qualquer forma, consideramos outras questões propostas por Almada para a análise da produção dos manuscritos, como as interações entre "o escrivão ou o secretário, as possibilidades de reprodução e guarda das cópias dos 
15. Almada (2018, p. 21).

16. Mawe (1978, p. 158).

17. Saint-Hilaire (1974, p. 29-30).

18. D’Orbigny (1976, p. 135). documentos produzidos, as condições para envio e circulação dos textos ou as viabilidades da escrita relativas à disponibilidade dos materiais necessários". ${ }^{15}$ Essa última proposição de longe é a mais explorada neste artigo. Assim, nossa abordagem priorizará especialmente a identificação e o uso das remessas de materiais enviados aos escritórios da administração geral e à casa da Intendência dos diamantes, entre eles o papel, as penas e as drogas utilizadas para a feitura de tinta.

\section{"DIFERENTES MIUDEZAS" IMPORTADAS}

O estudo das mercadorias importadas no período colonial não é uma novidade. No entanto, materiais como o papel raramente são referidos pela historiografia, menos ainda outros insumos necessários no cotidiano dos oficiais encarregados da escrita administrativa. Sabemos, porém, que eles eram amplamente comercializados na época moderna e constantemente enviados à América pelos principais fabricantes europeus, principalmente por intermédio dos homens de negócio de Portugal. Assim, chama atenção a ausência desses dispendiosos produtos nos relatos coevos de viajantes ou mesmo de historiadores do comércio, o que talvez tenha ocorrido, como já indicado, por serem tidos como dados ou óbvios demais. Dessa forma, o papel e outros materiais de escritório largamente utilizados em Minas Gerais parecem ter passado despercebidos em inúmeras ocasiões.

Desde o início do século XIX, viajantes e naturalistas registraram suas impressões a respeito da intensa circulação de produtos importados na América portuguesa, mas sem qualquer menção aos elementos materiais em pauta. John Mawe, por exemplo, ao passar pela comarca do Serro do Frio, Minas Gerais, relatou que suas "lojas estão abarrotadas de mercadorias de fábricas inglesas, assim como de presuntos, queijo, manteiga, cerveja e outros produtos de consumo". ${ }^{16}$ Saint-Hilaire descreveu situação semelhante quando percorreu o Arraial do Tejuco, um dos mais importantes daquela comarca, por sediar a Real Extração dos Diamantes. Segundo ele, as lojas do arraial "são providas de toda sorte de panos, nelas se encontram também chapéus, comestíveis, quinquilharia, louças, vidros e mesmo grande quantidade de artigos de luxo, que causam admiração [que] sejam procurados a uma tão grande distância do litoral"; além disso, destacou que "essas mercadorias são quase todas de fabricação inglesa e são vendidas em geral por preços muito módicos, tendo-se em vista a distância e a dificuldade de transporte". ${ }^{17}$ Em resumo, como ressaltou D'Orbigny, não há dúvidas de que as lojas e vendas de Minas Gerais fossem "sortidas de mercadorias europeias". ${ }^{18}$ 
Como é sabido, a entrada de mercadorias estrangeiras no Brasil consistia em importante e lucrativo negócio, pois elas eram essenciais para inúmeras atividades realizadas na colônia, assim como para a sobrevivência em geral. Para Virgílio Noya Pinto, tal como para os viajantes, as principais importações oriundas de Portugal eram constituídas de gêneros alimentícios, como as farinhas, os azeites, o bacalhau e o vinho. Posteriormente, passou-se a enviar mercadorias de luxo, como "veludos e sedas, brocados e tafetás, rendas e meias de seda, chapéus e fitas bordadas a ouro e prata". ${ }^{19}$ Também vinham outros tipos de tecidos, "sobretudo os panos baratos, para vestir o grosso da população brasileira, quer as de classe média e pobre, quer a escrava. São as baetas, os panos ordinários, as serafinas, as bretanhas e as camelas". ${ }^{20} \bigcirc$ autor informa, no entanto, que, "infelizmente, as referências sobre os carregamentos das frotas para o Brasil são de caráter geral, o que impede a utilização de quaisquer dados quantitativos". ${ }^{21}$ Do mesmo modo, de acordo com os dados levantados por Russell-Wood, de Portugal ao Brasil enviavam-se mais mercadorias de origem lusa, mas também de outras partes da Europa. Foram por ele elencados como os principais itens: azeite, farinha de trigo, bacalhau, vinhos, utensílios e bens manufaturados (que o autor não especifica). Entre os tecidos, são predominantes as baetas, as cambraias, as chitas de algodão e o linho. ${ }^{22}$ Alguns serviam à população mais abastada; outros, como a baeta e o linho, eram utilizados comumente para a confecção do vestuário dos escravizados.

Especificamente sobre a capitania de Minas Gerais, diversos estudos destacam seu vigoroso comércio de abastecimento, inicialmente com muito destaque para o mercado externo. Mafalda Zemella, apesar de indicar os diversos mercados que concorriam para o abastecimento da região mineradora, faz sucintas menções aos artigos provenientes de além-mar: vidros, espelhos, sedas, damascos, pelúcias, baixelas, vinhos, azeites, armas, sal e ferro seriam as mercadorias mais importadas da Europa. ${ }^{23}$ De forma semelhante, Cláudia Chaves aponta que "o comércio de artigos importados dedicava-se, principalmente, aos artigos de luxo (prata, louças, sedas etc.), vestuário, ferramentas, mobiliário e alguns gêneros alimentícios como queijos, azeite, vinhos etc." 24

De modo geral, as principais pesquisas dedicadas ao comércio interno se referem majoritariamente ao abastecimento alimentar. Assim, quando as importações são mencionadas, o são brevemente. Nesse sentido, José Newton Coelho Meneses considera que, além da produção interna de víveres, chegavam aos arraiais e vilas da comarca do Serro do Frio gêneros e mercadorias das capitanias de São Paulo e Rio de Janeiro, assim como "vários produtos importados da Metrópole, neles incluídos os alimentícios, como o 'sal do Reino', os embutidos ingleses e as bebidas". ${ }^{25}$ Para outra região da capitania, segundo Flávio Marcus da Silva,
19. Pinto (1979, p. 225).

20. Ibid., loc. cit.

21. Ibid., p. 227 .

22. Cf. Russell-Wood (1998).

23. Cf. Zemella (1990).

24. Chaves (1999, p. 39-40).

25. Meneses (2000, p. 176) 
26. Silva (2008, p. 83$)$.

27. Furtado (1999, p. 19).

28. Cf. Borrego (2010).

29. Arquivo Histórico do Tribunal de Contas de Portugal (1782-1789, p. 72) é certo que há indícios de uma entrada frequente de gêneros importados, como aguardente do reino, azeite de oliva, queijos do reino, bacalhau, sardinhas, vinho tinto, vinagre, ovas de tainha, camarão, arenques defumados, farinha do reino, manteiga de Flandres, gengibre, figos, passas, ameixas, amêndoas, entre outros. ${ }^{26}$

Podemos concluir que, nas palavras de Júnia Furtado, "a região mineradora importava todo tipo de produtos, entre secos, molhados; tecidos, alimentos, utensílios, papel, pólvora, couro, imagens, etc." ${ }^{27}$ A autora menciona o papel entre as cargas importadas justamente por ter analisado o comércio a partir da correspondência entre homens de negócio portugueses e seus agentes espalhados pela Europa, África e Brasil. Neste, o Rio de Janeiro desponta como a principal praça abastecedora não apenas dos núcleos mineradores, mas também de outras partes da colônia, como a cidade de São Paulo. Os comerciantes cariocas dispunham de toda sorte de mercadorias, em sua maioria importadas do Velho Mundo e revendidas na América, incluindo o papel, artigos de escritório e outras carregações diversificadas e valiosas. ${ }^{28}$ Aqui, fica evidente como as fontes de natureza financeira se constituem como interessantes pontos de partida para as análises centradas na cultura material da escrita. Seja como for, os materiais de escritório ainda são, de certa forma, invisíveis e pouco aludidos.

\section{PARA O EXPEDIENTE DO ESCRITÓRIO}

Após o monopólio sobre a produção e a comercialização dos diamantes, a Real Extração assumiu a condução de diversas tarefas relacionadas ao abastecimento, passando a importar da Europa ou adquirir de comerciantes cariocas tudo que fosse essencial à mineração, inclusive "papel, penas, drogas para tinta e diferentes miudezas" que se consomem "no expediente diário dos administradores". ${ }^{29}$ Assim, em 1772, para dar início aos trabalhos do novo empreendimento régio, fora nomeado o experiente Caetano José de Sousa como primeiro caixa-administrador. Ele tinha conhecimentos da administração dos diamantes porque havia ocupado cargo semelhante na gestão do sexto contrato do desembargador João Fernandes de Oliveira. Considerado homem de zelo e atividade no trato administrativo, imediatamente solicitou que fossem adquiridos os primeiros materiais de escritório. Todas as mercadorias destinadas à Real Extração, fossem do Reino ou do Rio de Janeiro, eram isentas de qualquer tributação. Para isso, uma ordem dos diretores, com aviso antes expedido à Casa da Índia, acompanhava as mercadorias para que a Mesa do Consulado 
do Rio de Janeiro as autorizasse com "despacho livre de quaisquer direitos, 30. Id., p. 240. contribuições ou encargos". ${ }^{30}$ Nessa mesma ordem está anexada a relação das mercadorias a serem desoneradas: "um caixão com quarenta resmas de papel ordinário para escrever e dez resmas de papel de Holanda também para escrever". ${ }^{31}$ Estes, como quaisquer produtos comprados e/ou expedidos de Lisboa, eram remetidos aos comissários da Administração no Rio de Janeiro. Dali, a cargo dos empregados de Francisco de Araúio Pereira e Companhia, as mercadorias seguiam em lombo de burro até o Arraial do Tejuco, onde eram entregues aos administradores da Real Extração.

\section{Quadro 1 - Materiais de escritório, Rio de Janeiro ${ }^{32}$}

\begin{tabular}{|l|l|l|}
\hline $\begin{array}{l}\text { Período de } \\
\text { registros }\end{array}$ & Produto & Quantidade \\
\hline 1772 & Livro de caixa com 200 folhas & 1 [unidade] \\
\hline 1772 & Livro de carregações com 200 folhas & 1 [unidade] \\
\hline 1772 & Livro de despenseiros de papel imperial com 400 folhas & 1 [unidade] \\
\hline 1772 & Livro diário e de razão com 300 e 500 folhas & 2 [unidades] \\
\hline 1772 & Livros com 50 e 200 folhas & 10 [unidades] \\
\hline 1772 & Livros de contas-correntes com 600 e 650 folhas & 2 [unidades] \\
\hline 1772 & Papel bom & 50 resmas \\
\hline 1774 & Papel de boa qualidade & 10 resmas \\
\hline 1772 & Papel de França ordinário & 5 resmas \\
\hline 1774 & Papel pequeno & 37 resmas \\
\hline 1774 & Penas de escrever [tipo] meia secretária & 500 [unidades] \\
\hline 1774 & Penas de escrever ordinárias & 1.000 [unidades] \\
\hline 1772 & Sinetes de prata & 3 [unidades] \\
\hline 1772 & Tesouras de escritório & 1 dúzia \\
\hline
\end{tabular}

A primeira remessa de mercadorias (Quadro 1) continha exclusivamente materiais de escritório, que foram comprados logo no primeiro mês por serem considerados primordiais para a boa administração das receitas e despesas da Real Extração. Assim, na carregação recebida pelos oficiais diamantinos, constam: livro de caixa com 200 folhas; livro de carregações com 200 folhas; livro de despenseiros de papel imperial com 400 folhas; livros de contas-correntes, um com 600 folhas e outro com 650; livros diários e de razão, um com 300 e outro com 500 folhas; e livros sem especificações, sendo 7 com 200 folhas e 3 com 
50 folhas. Neles se registravam todas as informações sobre o custeio e a produção anual de diamantes, inclusive as despesas com os próprios materiais de escritório.

Para entender por que esses livros eram utilizados pela nova administração, é preciso recordar que a Real Extração, além da Diretoria Geral em Lisboa, estava subordinada também ao Erário Régio, criado em 22 de dezembro de 1761, após a extinção da Casa dos Contos. Com a sua fundação, inauguraramse profundas alterações nos métodos de arrecadação e contabilidade das rendas régias, ao concentrar receita e despesa, antes dispersas, no mesmo lugar. Essa importante instituição do governo josefino-pombalino é considerada o principal instrumento de monopólio fiscal do Estado. Nas palavras de Kenneth Maxwell, - Tesouro Público representa "o elemento chave no esforço global de Pombal com vistas à racionalização e à centralização dos assuntos da Real Fazenda no Continente e Domínios Ultramarinos". ${ }^{33}$

Nesse contexto, o Erário Régio, segundo Luciano Figueiredo, foi justamente o responsável pela sistematização de um "novo método de escrituração, mais operacional e eficiente que a de partidas simples, prestação de contas usada pela Casa dos Contos, para permitir a avaliação de equilibrio ou desequilibrio entre débito e crédito; mais transparente também". ${ }^{34}$ Tratava-se do método das partidas dobradas, no qual toda operação possuía registros de crédito, colocado na página esquerda do livro, e de débito, na direita. Com isso, a partir de 1761, "passa-se a escrever nos livros Diário (em que eram registrados os assentos) e Mestre (em que se escreviam as receitas e despesas a cargo dessa repartição), que pertenciam a cada uma das contadorias". ${ }^{35}$

Esse método de escrituração das partidas dobradas foi adotado pela Junta Diamantina pois um dos objetivos centrais das autoridades era exatamente intensificar o controle sobre as receitas e despesas da administração diamantífera. O registro nos livros de contas-correntes, diários, mestres ou de razão era função do guarda-livros, oficial responsável pela contadoria da administração, em conjunto com o escrivão e o tesoureiro, pois tudo era deliberado em conjunto. Esses volumes eram enviados anualmente a Lisboa e, depois, eram cotejados com os balanços realizados semestralmente. Como mencionado, eles estão preservados no Arquivo Histórico do Tribunal de Contas de Portugal. São encadernados com um tecido azul, que nossos exames superficiais não deram conta de identificar num primeiro contato. De fato, aqui reside uma lacuna que certamente será aprofundada em pesquisas futuras, a fim de determinar os materiais exatos de tal encadernação. Por outro lado, os próprios manuscritos indicam quais tecidos poderiam ter sido utilizados, já que também foram importados, na mesma época, diversos panos na cor azul, além de barbantes, fitas, linhas e agulhas. 
Seja como for, em três dos livros estão registradas informações sobre saque de letras, remessas de cofres, venda e exportação de diamantes, pagamento de serviços diversos, ordenados e gratificações a oficiais, reembolsos e ressarcimentos a negociantes de diamantes, totalizando 535 entradas manuscritas. São eles: Diário segundo do livro mestre da Diretoria Geral da Real Extração dos Diamantes das Minas do Brasil, por conta da Fazenda Real; Borrador $1^{\circ}$ do diário do livro mestre da Diretoria Geral da Real Extração dos Diamantes das Minas do Brasil, por conta da Fazenda Real; e Borrador $2^{\circ}$ do diário do livro mestre da Diretoria Geral da Real Extração dos Diamantes. ${ }^{36}$ Estes últimos - os borradores - eram espécies de rascunhos, depois transcritos no Diário, cuja escrituração deveria ser perfeita e sem qualquer rasura, emenda ou erro. No entanto, em muitos casos, isso não foi possível. Mesmo havendo um padrão muito rigoroso nos lançamentos das informações contábeis, há casos de correções e acréscimos nas suas margens, sempre à esquerda de cada registro. Também por serem específicos para essa finalidade, não há neles muito empenho decorativo. No lugar dos ornamentos, há apenas rígidas linhas perfeitamente traçadas, esteticamente distantes da prática de adornar manuscritos da sociedade setecentista. Chama atenção, porém, a caligrafia quase sempre no mesmo estilo, demonstrando um padrão de legibilidade e uniformidade na escrita cursiva das palavras, além do diminuto uso de abreviaturas.

No Livro de registro de contas diversas relativas a mercadorias compradas em Lisboa, Porto e Rio de Janeiro respeitantes à Junta da Direção Geral da Real Extração dos Diamantes ${ }^{37}$ constam informações, como anuncia seu título, sobre as despesas relativas à importação de materiais essenciais ao trabalho diamantífero e à sobrevivência dos escravos e livres empregados nas inúmeras lavras de Minas Gerais. É composto por 81 faturas, contas e relações com a quantidade e o preço de itens adquiridos para o abastecimento, como alimentos e bebidas, tecidos para a feitura do vestuário, principalmente dos escravizados, insumos e instrumentos para mineração, ervas e substâncias para a produção de medicamentos, sendo este o maior volume de itens importados no período. É, aliás, a principal fonte explorada neste artigo.

Outros três livros contêm a correspondência entre as instâncias administrativas que comandavam a exploração dos diamantes nos dois lados do Atlântico. São intitulados: Livro $11^{\circ}$ ) do registro de ordens e cartas expedidas pela Junta de Direção Geral da Real Extração dos Diamantes [em Lisboa, para seus administradores gerais na Colônia]; Livro (2\%) do registro de ordens e cartas expedidas pela Junta de Direção Geral da Real Extração dos Diamantes [em Lisboa, para seus administradores gerais, na Colônia]; e Livro $\left(3^{\circ}\right)$ do registro de ordens e cartas expedidas pela Junta de Direção Geral da Real Extração dos Diamantes [em Lisboa,
36. Cf. Arquivo Histórico do Tribunal de Contas de Portugal (1782-1789, 1772$1783,1783-1805)$.

37. Id., 1772-1789. 
38. Ibid., 1771-1780, 17801789, 1789-1805.

39. Ibid., 1772-1787, 17731803a, 1773-1803b, 1805.

40. Ibid., 1772-1789.

41. O papel era caro pela constante falta da principal matéria-prima usada para sua confecção entre os séculos XIV e XIX: o trapo. Além disso, tinha alto custo pela grande quantidade de água utilizada na sua fabricação e, mais importante, pela enorme demanda, principalmente dos impressores. Para questões relacionadas a insumos, técnicas e condições do processo de fabricação do papel de trapo e às decisões que culminaram em novas soluções, como o uso da madeira, ver Febvre e Martin (2017, p. 80-85).

42. Arquivo Histórico do Tribunal de Contas de Portugal (1772-1789, p. 5, 23). para seus administradores gerais na Colônia]. ${ }^{38}$ No total, contêm 815 avisos, provisões, notícias, instruções, certidões, requerimentos, nomeações de oficiais, relações, balanços, mapas de rendimento, entre outros documentos.

Por fim, quatro livros somam 224 registros sobre envio e recebimento de cofres e venda e lapidação de diamantes, assim como indicam vestígios das relações econômicas e diplomáticas entre Portugal, Londres e Amsterdam, sobretudo no que se refere às negociações entre as principais companhias encarregadas do comércio de diamantes no mundo europeu. Originalmente foram denominados Caderno do registro dos saques de letras sobre os diretores gerais da Real Extração dos Diamantes; Livro das entradas e saídas dos diamantes na Junta da Direção Geral desta Real Extração; Livro de entrada e saída, à boca do cofre, dos diamantes e dinheiro pertencentes à Real Extração dos Diamantes por conta de Sua Majestade; e Faturas de diamantes. ${ }^{39}$

\section{Quadro 2 - Materiais de escritório, Lisboa e Rio de Janeiro ${ }^{40}$}

\begin{tabular}{|l|l|l|}
\hline Período de registros & Produto & Quantidade \\
\hline $1774,1779,1782$ & Papel de Holanda & 23 resmas \\
\hline 1772,1779 & Pastas de papelão & 98 [unidades] \\
\hline 1772,1774 & Penas de escrever & $1 \frac{1}{2}$ milheiro \\
\hline
\end{tabular}

Além dos livros de natureza contábil, para o início da administração também foram comprados materiais considerados caros no período, como o papel. ${ }^{41}$ Do Rio de Janeiro, em 1772 e 1774, foram remetidos papel bom, papel de boa qualidade, papel de França e papel pequeno (Quadro 1). No entanto, exceto no caso do papel de Holanda (Quadro 2), passados os primeiros anos da administração diamantina, a importação passou a ser feita exclusivamente de Lisboa, sob a justificativa de que isso seria mais vantajoso aos reais interesses, pois os preços praticados no Rio de Janeiro costumavam ser maiores, de acordo com os diretores da Real Extração. Conforme indicamos, quando eram enviados diretamente de Portugal, não incidia sobre esses itens nenhuma tributação, desde que fossem destinados exclusivamente à Extração Diamantina, ficando, assim, mais baratos do que os adquiridos de comerciantes cariocas. No Rio de janeiro, por exemplo, uma resma de papel de França, isto é, 500 folhas, custava 960 réis, ao passo que em Lisboa esse valor era de 550 réis. ${ }^{42}$ 
Quadro 3 - Materiais de escritório, Lisboa ${ }^{43}$

\begin{tabular}{|c|c|c|}
\hline Período de registros & Produto & Quantidade \\
\hline 1779,1782 & Bilhetes impressos & 8 resmas \\
\hline 1775 & Livros encadernados de conhecimentos & 18 [unidades] e 1 resma \\
\hline $1782,1784,1785$ & Papel AP (apergaminhado) $1^{a}$ sorte & 140 resmas \\
\hline 1782 & Papel AP (apergaminhado) $2^{a}$ sorte & 20 resmas \\
\hline $1774,1775,1780$ & Papel de embrulhar & 38 resmas \\
\hline 1775 & Papel de França & 12 resmas \\
\hline 1779, 1789 & Papel de França - marca grande & 18 resmas \\
\hline 1779 & Papel de França pequeno & 8 resmas \\
\hline 1789 & Papel de Gênova & 10 resmas \\
\hline 1785 & Papel de Holanda bastardo & 4 resmas \\
\hline $1775,1784,1785$ & Papel de Holanda - marca grande & 26 resmas \\
\hline 1779 & Papel de Luca $1^{a}$ sorte & 60 resmas \\
\hline 1774,1776 & Papel de Luca & 138 resmas \\
\hline 1776 & Papel imperial & 1 resma \\
\hline 1774 & Papel pardo & 2 resmas \\
\hline 1782 & Papel pardo - marca grande nas cabeças & 2 resmas \\
\hline 1782 & Papel pardo nas cabeças & 4 resmas \\
\hline 1774 & Penas de escrever de linha verde & 16 centos \\
\hline 1774 & Tesouras $n^{\circ} 13$ & 6 dúzias \\
\hline 1774 & Tesouras $n^{\circ} 14$ & 6 dúzias \\
\hline 1774 & Tesouras $n^{\circ} 15$ & 6 dúzias \\
\hline
\end{tabular}

43. Id., 1772-1789.

44. Ibid., p. 9, 13, 72 .

45. Cf. Hunter (2011).

Por isso, entre 1774 e 1789, os seguintes tipos passaram a ser enviados somente de Portugal (Quadro 3): papel AP (apergaminhado) $1^{a}$ sorte; papel AP (apergaminhado) $2^{a}$ sorte; papel de embrulhar; papel de França; papel de França - marca grande; papel de França pequeno; papel de Gênova; papel de Holanda bastardo; papel de Holanda - marca grande; papel de Luca $1^{a}$ sorte; papel de Luca; papel imperial; papel pardo; papel pardo - marca grande nas cabeças; papel pardo nas cabeças. Entre estes, os papéis de Holanda eram os mais caros, com preço variando entre 3.000 e 3.800 réis por resma. Já a resma do papel de Luca comum, um dos mais comprados pela Real Extração, custava em média 1.300 réis em Lisboa. ${ }^{44}$ Quanto à atribuição de características aos diversos tipos de papel, era uma prática comum no seu processo de produção, sendo definidas a partir de seus tamanhos, destinos e usos específicos, assim como pela qualidade do material e pelos preços. ${ }^{45}$ Para outras questões físicas e formais ainda desconhecidas, como a 
46. Marques (2008, p. 41).

47. Cf. Febvre; Martin, op. cit.

48. Sobre a invenção do papel na China e seu percurso da Ásia à Europa, cf. Carter (1955) e Basbanes (2013).

49. Febvre; Martin, op. cit., p. 78. identificação ou a confirmação de filigranas ou marcas d'água, pontusais e vergaturas, será necessário recorrer futuramente a exames aprofundados a partir da metodologia de análise material indicada no início deste artigo. Além de auxiliar na identificação de manuscritos e impressos, o estudo desses aspectos, como ressalta Luís Alves Marques, é fundamental na medida em que possibilita "datar documentos, identificar tamanhos e qualidade das folhas de papel, e, consequentemente, orientarnos para o local de produção e ter uma noção da sua circulação comercial" ${ }^{46}$ Esse procedimento a partir da materialidade do documento seria, portanto, complementar às informações já levantadas por esta pesquisa.

Como sugere a origem desses suportes, aqui destacada, parte considerável deles não foi produzida em Portugal, embora muitos tenham sido denominados genericamente, sem qualquer indício que aponte de forma explícita sua procedência. Como havia uma intensa produção de papel nos territórios europeus da época moderna, é possivel identificar seus principais fabricantes, o que confirma as origens do papel importado pelas autoridades portuguesas. Por isso, vale a pena discorrer brevemente sobre a circulação do objeto em pauta. Os poucos estudos sobre o assunto são unânimes em afirmar que a ltália figurava como o mais importante centro de difusão desse novo material. Aliás, os italianos são considerados uns dos primeiros produtores do papel na Europa. Segundo Lucien Febvre e Henri-Jean Martin, embora existam registros de fábricas na Espanha no século XII, a indústria papeleira teve maior relevo na ltália. ${ }^{47}$ Esse suporte, até então de qualidade inferior se comparado ao pergaminho, teria sido trazido por mercadores que mantinham relações com os árabes, que, por sua vez, foram os responsáveis por comercializar a invenção chinesa. ${ }^{48}$ Apesar de sua aparência frágil, passou a chegar em profusão aos portos italianos e foi cada vez mais utilizado pelos notários genoveses e pelas chancelarias. No entanto, devido ao risco de destruição das informações, o imperador Frederico II proibiu a utilização de papel em atos públicos. Seja como for, esse material continuou a circular na ltália, onde, como dito, se constituíram os grandes centros de fabricação papeleira, especialmente a partir do século XIV.

Nesse contexto, os produtores de Fabriano se destacaram pela rapidez com que melhoraram a qualidade e o rendimento do papel. Na segunda metade do século XIV, surgiram novos eixos especializados nesse suporte: "em Voltri, em Pádua, em Treviso e em Gênova e [se] formam muito cedo dois outros grandes centros, na Ligúria, ao redor de Gênova, e nos Estados de Veneza, ao redor do Lago de Garda". ${ }^{49}$ Ainda de acordo com Febvre e Martin, entre 1362 e 1386, papéis de filigrana italiana eram facilmente encontrados na Espanha, França, Holanda e Bélgica. No mesmo período, tendo os genoveses e venezianos como os principais negociantes e difusores de suas técnicas de fabricação, o papel começou a substituir 
o pergaminho em todo o território europeu, sendo seu uso bastante comum na Suíça 50. Ibid., p. 79. e, em menor grau, no norte da França; depois nos Países Baixos e na Alemanha do norte. Não demorou, porém, para que sua fabricação tomasse fôlego fora da ltália, mas ainda sob tutela de comerciantes italianos estabelecidos no exterior, que "não hesitam, diante da crescente demanda, em mandar vir, de suas regiões, os primeiros técnicos encarregados de ensinar seu ofício". 50

No século XV, a região de Troyes e os arredores de Paris eram responsáveis pelo abastecimento de papel na França. A Itália, entretanto, continuou a fornecer papel para Espanha, Inglaterra, Países Baixos, Áustria, Alemanha e Suíça, localidades onde já funcionavam moinhos. Conforme mencionado, a partir daí, "depósitos de papel italiano existiam em todos os grandes centros". ${ }^{51}$ Desse modo, entre os séculos XIV e XVII, "as papelarias multiplicam-se para responder a uma demanda crescente; enquanto a falta de matéria-prima limita o desenvolvimento dos grandes centros, criam-se novos estabelecimentos continuamente nas regiões que até então ignoravam a arte de fazer papel". ${ }^{52}$ Nesse período, a despeito do insuficiente fornecimento de trapo e das críticas pelo excessivo uso de água, os holandeses despontaram como os principais concorrentes dos italianos. No século XVIII, já havia fábricas de papel em quase toda a Europa ocidental. Apesar da multiplicação delas, a ltália continuou em plena atividade, pois o consumo era cada vez maior.

A respeito da indústria papeleira em Portugal, não é um exagero afirmarmos que ainda a conhecemos muito pouco. De acordo com Arnaldo Faria de Ataíde e Melo, em trabalho publicado em 1926, "a sua produção, se a houve, deve ter sido muito fraca". ${ }^{53} \bigcirc$ autor destaca que ali o grande desenvolvimento dessa indústria remonta ao século XIX, quando os moinhos e fábricas se multiplicaram nas cidades portuguesas. Antes disso, as informações encontradas nas fontes são esparsas. No século XV, por exemplo, "sabe-se da existência de várias concessões para montagens de moinhos e privilégios para transporte de trapo". ${ }^{54}$ Nos séculos seguintes, houve várias tentativas de estabelecer oficinas para a produção de papel. Já no século XVIII, durante o reinado de d. João $V$, registros dão conta da fabricação de papel em maior escala "na Vila de Lousã junto à cidade de Coimbra, em que se faz papel ordinário, florete e imperial". ${ }^{55}$ Aliás, é justamente nesse período que a indústria papeleira teria tomado impulso nos territórios lusos, ficando seu comércio e seu uso controlados por legislação específica a partir de 1766.56 Contudo, apesar das notícias de moinhos dedicados à manufatura de papel nos séculos anteriores, é certo que até o século XIX Portugal ainda importava papel de países como Itália, França, Alemanha, Inglaterra e Países Baixos, ou mesmo comprava da produção local com a marca dos irmãos Magnani, italianos que distribuíam seu prestigioso papel na cidade de Lisboa durante a primeira metade 
57. Cf. Santos (2014).

58. Max de Oliveira, op. cit., p. 61 .

59. Febvre; Martin, op. cit., p. 89.

60. Cf. Bouza (2001).

61. Cunha (2015, p. 23) daquela centúria. ${ }^{57}$ Como indicado nos quadros de importação de material de escritório da Real Extração, os portugueses de fato adquiriam papel principalmente da França, Holanda, Gênova e Luca. Além disso, podemos conjecturar que a maior parte do papel que circulou na América portuguesa também era originário das localidades supracitadas, uma vez que, no Brasil, a produção desse item só teve lugar após a transferência da Corte no início do Oitocentos, tendo como um dos pioneiros o frei José Mariano da Conceição Veloso. ${ }^{58}$

Quanto ao seu uso nas sociedades modernas, o papel era consumido nas universidades, na administração burocrática, nas negociações comerciais e em toda sorte de trabalhos, de modo que até mesmo "donos de armarinhos, de mercearias, de velas" o vendiam. ${ }^{59} \mathrm{Na}$ Península lbérica, o papel era bastante demandado, como indica o trabalho de Fernando Bouza sobre a circulação de manuscritos entre os séculos XVI e XVII. Nos papéis escritos à mão ou impressos, não corriam apenas cartas, conversas íntimas, petições e pasquins, mas também assuntos da monarquia. ${ }^{60}$ As notícias e informações administrativas dos reinos ibéricos ou de suas possessões ultramarinas, uma vez registradas no papel, deram origem, como referido no início deste artigo, a uma gigantesca massa documental que, naquele período, tinha um uso bastante instrumental no exercício da política e da gestão fiscal.

Na América portuguesa, focando apenas as questões aludidas, o papel e demais materiais de escritório eram utilizados em todos os âmbitos da administração. Em Minas Gerais, para outra importante instituição criada na segunda metade do século XVIII, a Junta da Real Fazenda, esses elementos eram indispensáveis para o registro das informações relativas à arrematação e arrecadação de contratos e de todos os direitos e tributos reais da capitania, assim como para "a provisão das serventias dos ofícios da fazenda e a expedição das folhas dos ordenados eclesiásticos, civis e militares, além daquelas de natureza extraordinária". ${ }^{61}$ Não por acaso, parte considerável do referido acervo do Arquivo Histórico do Tribunal de Contas de Portugal é constituída por diversos códices respeitantes ao controle financeiro desempenhado pela Real Fazenda.

Obviamente, o papel utilizado para a correspondência entre as autoridades coloniais e portuguesas está preservado também nos arquivos brasileiros, sobretudo no Arquivo Público Mineiro, onde há inúmeros originais e cópias de documentos existentes nos códices do Arquivo Histórico do Tribunal de Contas de Portugal, a maioria provavelmente produzida por oficiais da Real Extração e enviada ao governo da capitania, já que tais cartas possuem, em muitos casos, a mesma caligrafia. Ademais, conforme indicamos, a comunicação mensal entre as principais instâncias administrativas - a do Tejuco, a Diretoria em Lisboa e o Erário Régio - era obrigatória. A falta, por parte dos funcionários, 
de comunicação e de notícias sobre o estado da administração muitas vezes era motivo de repreensão pelas autoridades superiores. De 1772 a 1805, é grande o volume de cartas trocadas entre as instituições citadas. Considerando-se apenas a correspondência entre as autoridades diretamente ligadas à Real Extração existente no referido acervo, fica evidente a importância dada à comunicação administrativa e aos anseios de controlar, por meio da escrita, as rendas reais provenientes dos espaços coloniais. Nesse sentido, o suporte é tão importante quanto o conteúdo escrito e, como destaca Lissa Roberts em estudo sobre a circulação de informações e ideias na Europa moderna, o conhecimento não existe ou viaja por si só em nosso mundo material. ${ }^{62}$ Para tanto, é necessário "um suporte físico, seja um humano, um livro, uma ilustração, uma máquina ou um instrumento", tal como historiadores do livro e da leitura como Roger Chartier e Robert Darnton já haviam indicado. 63 Por isso, nas belas palavras de Arnaldo Faria de Ataíde e Melo, "se o papel é um maravilhoso instrumento de difusão e vulgarização, é também o conservador e o guardião do passado". ${ }^{64}$

No Distrito Diamantino, além do escritório da Real Extração, funcionavam concomitantemente dezenas de lavras ou serviços de mineração, como eram chamados. Muitas vezes estabelecidos longe do centro administrativo, os serviços se constituíam como arraiais provisórios, onde escravos, oficiais mecânicos, feitores, pedestres, guardas e administradores subalternos viviam e trabalhavam até o esgotamento das lavras. Assim, de modo geral, além das fábricas de mineração, cada serviço contava com paióis, moinhos, currais, armazéns, oficinas, rancharias, chácaras, senzalas, capelas, boticas e pequenos escritórios. Ali, esses materiais eram usados no expediente dos oficiais, considerando sempre as noções de boa administração e de controle financeiro que permeavam todos os setores da produção diamantífera. Tudo precisava ser registrado a fim de prestar contas posteriormente, até mesmo o consumo, no hospital do Distrito, de medicamentos e alimentos considerados caros, como a galinha utilizada para a refeição dos doentes.

Para a escrita nesses dispendiosos suportes, grande quantidade de penas foi comprada entre 1772 e 1774 (Quadros 1, 2 e 3). Somando-se as remessas do Rio de Janeiro e de Lisboa, a Administração Diamantina adquiriu 3.000 penas de escrever, sendo 500 do tipo "meia secretária", 1.000 "ordinárias" e 1.500 "penas de escrever comuns", além de mais de 16 centos de "penas de escrever de linha verde", também provenientes de Lisboa no início do monopólio dos diamantes. Como dito, pela uniformidade da caligrafia dos manuscritos em pauta fica evidente que os homens dominavam as artes da pena. Segundo Márcia Almada, escrever bem com a pena exigia não só o esforço de atingir determinado padrão de ortografia e gramática, mas também treinar a escrita dos caracteres com elegância, devendo-se, 
65. Cf. Almada (2012)

66. Id., 2006, p. 56-57.

67. Arquivo Histórico do Tribunal de Contas de Portugal (1772-1789, p. 82).

68. Almada (2006, p. 5657).

69. Arquivo Histórico do Tribunal de Contas de Portugal (1772-1789, p. 82)

70. Silva (1789, v. 2, p. 76).

71. Bluteau (1712, v. 2, p. 119).

72. Arquivo Histórico do Tribunal de Contas de Portugal (1772-1789, p. 19, 38, $66,83)$.

73. Cf. Arquivo Histórico do Tribunal de Contas de Portugal (1772-1789).

74. Estas são algumas das medidas mais usuais no século XVIII. Como dito, uma libra equivale a 459 gramas; e uma arroba, 14.668 quilos (Meneses, 2000, p. 241). para isso, conhecer e escolher bem o material a ser utilizado, incluindo a qualidade da pena da ave e seu correto corte. ${ }^{65}$ No entanto, os administradores não precisavam se preocupar com isso, pois contavam com milhares delas disponíveis no "armazém".

Nesse processo, a única coisa que os funcionários da Real Extração precisavam preparar era a tinta, que, por ser de fácil confecção, eles não recebiam pronta para uso. Comumente, junto com o papel e as penas para escrever, chegavam a Minas Gerais substâncias minerais e vegetais para sua feitura (Quadro 4). Nas extensas cargas de drogas de botica enviadas do Rio de Janeiro ou da Europa, entre 1772 e 1789, constam as principais substâncias para a produção da conhecida tinta ferrogálica, como a goma arábica, "uma solução de coloração dourada extraída da seiva de Acácias nativas do norte da África". 60 Em Lisboa, seu preço médio era de 400 réis por cada libra, ou seja, 459 gramas. ${ }^{67}$ Essa substância tinha a função de "manter o pigmento em suspensão no líquido", evitando seu depósito no fundo do pote, além de deixar a tinta mais grossa e, portanto, de mais fácil aplicação com a pena ou o pincel. ${ }^{68} \mathrm{~A}$ galha, por sua vez, custava cerca de 360 réis por libra em Portugal. ${ }^{69} \mathrm{~A}$ partir dela se extraía o tanino, isto é, uma essência geralmente retirada de cascas de árvores, preferencialmente com ação de insetos, que, "misturada com caparrosa, faz tinta preta". 70 Por fim, era necessária a caparrosa ou caparrosa verde, nomes dados ao sulfato ferroso. Segundo Bluteau, trata-se de sais minerais extraídos nas minas de cobre e utilizados "para fazer tinta de escrever". 71 No Rio de Janeiro, seu preço costumava variar entre 60 e 80 réis por libra; já em Lisboa, não passava de 25 réis. ${ }^{72}$ As drogas para tinta, portanto, eram encontradas facilmente no Rio de Janeiro, mas, como no caso do papel, as autoridades faziam questão de enviá-las de Portugal pelo menor preço.

\section{Quadro 4 - Drogas para tinta, Lisboa e Rio de Janeiro ${ }^{73}$}

\begin{tabular}{|l|l|l|}
\hline Período de registros & Produto & Quantidade \\
\hline $\begin{array}{l}1774,1778,1779,1780,1781, \\
1782,1785,1789\end{array}$ & Goma arábica & 1 arroba e 161 libras $^{74}$ \\
\hline $1774,1776,1782,1789$ & Galha & 7 arrobas e 298 libras \\
\hline $1778,1781,1782,1789$ & Caparrosa & $51 \frac{1}{2}$ arrobas e 106 libras \\
\hline 1774,1782 & Caparrosa verde & 10 libras \\
\hline $1772,1774,1776,1779$ & Casca de romã vermelha & 1 1⁄2/2 arroba e 60 libras \\
\hline 1774 & Açúcar & 4 libras \\
\hline $1779,1780,1781,1782,1789$ & Pedra-ume & 2 arrobas e 104 libras \\
\hline
\end{tabular}


Havia uma grande variedade de receitas para a tinta utilizada da ldade Média até o século XIX, mas adaptáveis de acordo com a disponibilidade de materiais em cada região. De maneira geral, segundo Márcia Almada, os referidos produtos básicos eram misturados com água ou vinho branco, criando "uma reação química entre o ácido tânico e o sulfato ferroso em meio aquoso" ${ }^{75}$ Essas observações são retiradas da instrução de Manoel de Andrade Figueiredo no seu manual para aprender a escrever. Sua receita inclui cascas de romã vermelha que, "feita em bocadinhos, ajudará a fazer bom preto". 76 Desse modo, "os principais componentes do tanino são os ácidos gálicos, que, junto com o sulfato ferroso, produzem um pigmento preto após exposição ao oxigênio", de modo que sua intensidade aumenta de fato quando aplicado ao papel. ${ }^{77}$ Para que esse processo se complete, isto é, resulte efetivamente em tinta, é necessário adicionar algum aglutinante, "que tem a função de the dar corpo e permitir a aplicação com a pena da escrita, fixando-se ao suporte". ${ }^{78}$ De acordo com Manoel de Andrade Figueiredo, esse aglutinante poderia ser o açúcar, que "não só faz unir a tinta ao papel, mas também impede a que não caia da pena", além da pedra-ume, que "é precisa porque impede o passar a tinta" ${ }^{79}$ Por isso, entre as despesas de escritório da Real Extração constam o açúcar, "para tinta de escrever para o expediente do escritório", 80 e a pedra-ume, embora esta também fosse adquirida para a produção de medicamentos para os doentes que se encontravam no hospital do Distrito Diamantino.

Além do papel, das penas de escrever e das drogas para tinta, outros materiais foram comprados para uso do expediente da Real Extração, conforme listamos nos Quadros 1, 2 e 3. São eles: sinetes de prata, para selar cartas e documentos sigilosos; tesouras de escritório de tamanhos diversos; e pastas de papelão. Também foram enviados ao Tejuco os famosos bilhetes encadernados em livros, que funcionavam como uma espécie de moeda-papel no Distrito Diamantino. Eles eram impressos em Lisboa, na oficina de Miguel Menescal da Costa, que por vezes também fornecia papel à Diretoria Geral. ${ }^{81}$ Segundo Joaquim Felício dos Santos, os bilhetes eram usados quando a Administração não possuía fundos e precisava comprar mantimentos, pagar aluguéis de escravos, jornais dos trabalhadores, ordenados de empregados ou qualquer outra despesa corrente. ${ }^{82}$ A Real Extração entregava os bilhetes - ou "letras" como eram mais conhecidos - aos credores, que eram pagos quando estivesse disponível a ajuda de custo fornecida pela Provedoria de Vila Rica. A operação funcionava da seguinte forma: "de cada quantia devida se faziam dois bilhetes idênticos: um, que se cortava pela tarja, que havia no meio da folha, e se entregava ao credor; o outro, que ficava no livro, servia de registro para a conferência que se devia fazer na ocasião do pagamento". ${ }^{83}$ As transações decorrentes desse processo,
75. Almada (2006, p. 55).

76. Figueiredo (2009, p. 29)

77. Almada (2006, p. 55).

78. Ibid., p. 56.

79. Figueiredo (2009, p. 29).

80. Arquivo Histórico do Tribunal de Contas de Portugal (1782-1789, p. 57).

81. Id., p. 156-157.

82. Cf. Santos (1976).

83. Bessa (1981, p. 63). 
por sua vez, eram registradas no citado Caderno do registro dos saques de letras sobre os diretores gerais da Real Extração dos Diamantes.

À guisa de conclusão, diferentemente dos registros escritos possibilitados pelos papéis e livros de contabilidade, os materiais de escritório não perduraram ao longo do tempo, embora agora saibamos da sua existência nas Minas Gerais do século XVIII. De qualquer forma, nossa intenção foi mesmo a de desvelar a circulação desses insumos a partir da documentação manuscrita preservada, sobretudo, pelo Arquivo Histórico do Tribunal de Contas de Portugal. Por isso, ainda que não tenhamos acessado fisicamente os elementos materiais estudados, muitas informações coletadas podem subsidiar outras pesquisas que busquem compreender aspectos variados de determinada sociedade do passado, em especial as relacionadas às formas de viver e de explorar diamantes no período colonial. Para isso, além das fontes escritas, o acervo do Museu do Diamante, que ocupa um prédio construído em 1749 no antigo Arraial do Tejuco, atual cidade de Diamantina, constitui-se como um percurso obrigatório de pesquisa. Seu acervo, de tipologias diversas, abriga inúmeros artefatos de arte sacra, entre pinturas e esculturas, mobiliário e utensílios domésticos, instrumentos musicais, armaria, transporte, indumentária, tecelagem, numismática e, claro, mineralogia. Enfim, há muito que se pesquisar sobre a vida material na terra dos diamantes. 


\section{REFERÊNCIAS}

FONTES MANUSCRITAS

ARQUIVO HISTÓRICO DO TRIBUNAL DE CONTAS DE PORTUGAL. Erário Régio. Diário segundo do livro mestre da diretoria geral da Real Extração dos Diamantes das Minas do Brasil, por conta da Fazenda Real: 1782-1789. Lisboa: Arquivo Histórico do Tribunal de Contas de Portugal, 1782-1789. Livro 4.084.

ARQUIVO HISTÓRICO DO TRIBUNAL DE CONTAS DE PORTUGAL. Erário Régio. Borrador $1^{\circ}$ do livro mestre da Diretoria Geral da Real Extração dos Diamantes das Minas do Brasil, por conta da Fazenda Real: 1772-1783. Lisboa: Arquivo Histórico do Tribunal de Contas de Portugal, 1772-1783. Livro 4.085.

ARQUIVO HISTÓRICO DO TRIBUNAL DE CONTAS DE PORTUGAL. Erário Régio. Borrador $2^{\circ}$ do diário do livro mestre da Diretoria Geral da Real Extração dos Diamantes: 1783-1805. Lisboa: Arquivo Histórico do Tribunal de Contas de Portugal, 1783-1805. Livro 4.086.

ARQUIVO HISTÓRICO DO TRIBUNAL DE CONTAS DE PORTUGAL. Erário Régio. Livro de registro de contas diversas relativas a mercadorias compradas em Lisboa, Porto e Rio de Janeiro respeitantes à Junta da Direção Geral da Real Extração dos Diamantes: 1772-1789. Lisboa: Arquivo Histórico do Tribunal de Contas de Portugal, 1772-1789. Livro 4.087.

ARQUIVO HISTÓRICO DO TRIBUNAL DE CONTAS DE PORTUGAL. Erário Régio. Livro $\left(1^{\circ}\right)$ do registro de ordens e cartas expedidas pela Junta de Direção Geral da Real Extração dos Diamantes [em Lisboa, para seus administradores gerais na Colônia]: 1771-1780. Lisboa: Arquivo Histórico do Tribunal de Contas de Portugal, 1771-1780. Livro 4.088.

ARQUIVO HISTÓRICO DO TRIBUNAL DE CONTAS DE PORTUGAL. Erário Régio. Livro $\left(2^{\circ}\right)$ do registro de ordens e cartas expedidas pela Junta de Direção Geral da Real Extração dos Diamantes, em Lisboa, para seus administradores gerais, na Colônia:1780-1789. Lisboa: Arquivo Histórico do Tribunal de Contas de Portugal, 1780-1789. Livro 4.089

ARQUIVO HISTÓRICO DO TRIBUNAL DE CONTAS DE PORTUGAL. Erário Régio. Livro ( $3^{\circ}$ ) do registro de ordens e cartas expedidas pela Junta de Direção Geral da Real Extração dos Diamantes [em Lisboa, para seus administradores gerais na Colônia]: 1789-1805. Lisboa: Arquivo Histórico do Tribunal de Contas de Portugal, 1789-1805. Livro 4.090. 
ARQUIVO HISTÓRICO DO TRIBUNAL DE CONTAS DE PORTUGAL. Erário Régio. Caderno do registro dos saques de letras sobre os diretores gerais da Real Extração dos Diamantes: 1772-1787. Lisboa: Arquivo Histórico do Tribunal de Contas de Portugal, 1772-1787. Livro 4.091 .

ARQUIVO HISTÓRICO DO TRIBUNAL DE CONTAS DE PORTUGAL. Erário Régio. Livro das entradas e saídas dos diamantes na Junta da Direção Geral desta Real Extração:1773-1803a. Lisboa: Arquivo Histórico do Tribunal de Contas de Portugal, 1773-1803. Livro 4.092.

ARQUIVO HISTÓRICO DO TRIBUNAL DE CONTAS DE PORTUGAL. Erário Régio. Livro de entrada e saída, à boca do cofre, dos diamantes e dinbeiro pertencentes à Real Extração dos Diamantes por conta de Sua Majestade:1773-1803. Lisboa: Arquivo Histórico do Tribunal de Contas de Portugal, 1773-1803b. Livro 4.093.

ARQUIVO HISTÓRICO DO TRIBUNAL DE CONTAS DE PORTUGAL. Erário Régio. Faturas de diamantes: 1805. Lisboa: Arquivo Histórico do Tribunal de Contas de Portugal, 1805. Livro 4094.

FONTES IMPRESSAS

BLUTEAU, Raphael. Vocabulario portuguez e latino: aulico, anatomico, architectonico [...]. Coimbra: Collegio das Artes da Companhia de Jesus, 1728. v. 2.

D’ORBIGNY, Alcide. Viagem pitoresca através do Brasil. Tradução: David Jardim. Belo Horizonte: Itatiaia; São Paulo: Edusp, 1976.

FIGUEIREDO, Manoel de Andrade. Nova escola para aprender a ler, escrever e contar. Valladolid: Maxtor, 2009.

MAWE, John. Viagens ao interior do Brasil. Tradução: Solena Benevides Viana. Belo Horizonte: Itatiaia; São Paulo: Edusp, 1978.

SAINT-HILAIRE, Auguste de. Viagem pelo distrito dos diamantes e litoral do Brasil. Tradução: Leonam de Azevedo Penna. Belo Horizonte: Itatiaia; São Paulo: Edusp, 1974.

SILVA, Antonio Moraes. Diccionario da lingua portugueza: recompilado dos vocabularios impressos ate agora, e nesta segunda edição novamente emendado e muito acrescentado. Lisboa: Typographia Lacerdina, 1789. v. 2. 
LIVROS, ARTIGOS E TESES

ALMADA, Márcia. Livros manuscritos iluminados na era moderna: compromissos de irmandades mineiras, século XVIII. 2006. 171 f. (Mestrado em História) - Faculdade de Filosofia e Ciências Humanas, Universidade Federal de Minas Gerais, Belo Horizonte, 2006.

ALMADA, Márcia. Das artes da pena e do pincel: caligrafia e pintura em manuscritos no século XVIII. Belo Horizonte: Fino Traço, 2012.

ALMADA, Márcia. Cultura material da escrita ou o texto como artefato. In: CONCEIÇÃO, Adriana Angelita da; MEIRELLES; Juliana Gesuelli (orgs.). Cultura escrita em debate: reflexões sobre o império português na América, séculos XVI a XIX. Jundiaí: Paco, 2018. p. 19-41.

BASBANES, Nicholas A. On paper: the everything of its two-thousand-year history. New York: Alfred A. Knopf, 2013.

BESSA, Antônio Luiz de. História financeira de Minas Gerais em 70 anos de república. Belo Horizonte: Imprensa Oficial, 1981. v. 1.

BORREGO, Maria Aparecida de Menezes. A teia mercantil: negócios e poderes em São Paulo colonial (1711-1765). São Paulo: Alameda, 2010.

BOSCHI, Caio César; QUINTÃO, Régis Clemente. Minas Gerais nos arquivos históricos de Portugal. Belo Horizonte: PUC Minas, 2019.

BOUZA, Fernando Alvarez. Corre manuscrito: una historia cultural del siglo de oro. Madrid: Marcial Pons, 2001.

CARTER, Thomas Francis. The invention of printing in China and its spread westward. 2. ed. New York: Columbia University Press, 1955.

CHAVES, Cláudia Maria das Graças. Perfeitos negociantes: mercadores das Minas setecentistas. São Paulo: Annablume, 1999.

CUNHA, Alexandre Mendes. A Junta da Real Fazenda em Minas Gerais em seu diálogo com o Erário Régio. In: BOSCHI, Caio César; QUINTÃO, Régis Clemente. Minas Gerais no Arquivo Histórico do Tribunal de Contas de Portugal. Belo Horizonte: PUC Minas, 2015. p. 18-27. 
FEBVRE, Lucien; MARTIN, Henri-Jean. A questão preliminar: o aparecimento do papel na Europa. In: FEBVRE, Lucien; MARTIN, Henri-Jean. O aparecimento do livro. Tradução: Fulvia M. L. Montetto e Guacira Marcondes Machado. São Paulo: Editora da Universidade de São Paulo, 2017. p. 75-95.

FIGUEIREDO, Luciano. O Erário Régio: uma breve introdução. In: BOSCHI, Caio César; QUINTÃO, Régis Clemente. Minas Gerais no Arquivo Histórico do Tribunal de Contas de Portugal. Belo Horizonte: PUC Minas, 2015. p. 11-17.

FURTADO, Júnia Ferreira. Homens de negócios: a interiorização da metrópole e do comércio nas Minas setecentistas. São Paulo: Hucitec, 1999.

GONÇALVES, Marina Furtado. Adaptação do Protocolo Idap para a análise material de documentos avulsos da Coleção Casa dos Contos do Arquivo Público Mineiro. In: GRAMMONT, Guiomar; MENESES, José Newton Coelho; ALMADA, Márcia (orgs.). Anais do I Seminário Internacional Cultura Escrita no Mundo Moderno. Belo Horizonte: Universidade Federal de Minas Gerais, 2019. p. 36-43.

HUNTER, Dard. Papermaking: the history and technique of an ancient craft. New York: Dover Publications, 2011.

MARQUES, Luís Alves. O papel e as marcas de água nas cartas de Luís Joaquim dos Santos Marrocos. In: MARROCOS, Luís Joaquim dos Santos. Cartas do Rio de Janeiro: 1811-1821. Lisboa: Biblioteca Nacional, 2008. p. 41-61.

MAX DE OLIVEIRA, George Gleyk. Estudo do papel e das filigranas e sua ocorrência em manuscritos dos séculos XVIII e XIX na capitania e província de Mato Grosso. 2014. $300 \mathrm{f}$. (Mestrado em Estudos de Linguagem) - Instituto de Linguagem, Universidade Federal de Mato Grosso, Cuiabá, 2014.

MAXWELL, Kenneth. Marquês de Pombal: paradoxo do iluminismo. Tradução: Antônio de Pádua Danesi. Rio de Janeiro: Paz e Terra, 1996.

MELO, Arnaldo Faria de Ataíde e. O papel como elemento de identificação. Lisboa: Biblioteca Nacional, 1926.

MENESES, José Newton Coelho. O continente rústico: abastecimento alimentar nas Minas Gerais setecentistas. Diamantina: Maria Fumaça, 2000.

MENESES, José Newton Coelho. Apresentação. Varia Historia, Belo Horizonte, v. 27, n. 46, p. 397-404, 2011. 
MENESES, José Newton Coelho; BORREGO, Maria Aparecida de Menezes. Introdução: o testemunho das coisas úteis e duráveis. Anais do Museu Paulista: História e Cultura Material, São Paulo, v. 26, p. 1-4, 2018.

MILlER, Daniel. Trecos, troços e coisas: estudos antropológicos sobre a cultura material. Tradução: Renato Aguiar. Rio de Janeiro: Zahar, 2013.

PINTO, Virgílio Noya. O ouro brasileiro e o comércio anglo-português: uma contribuição aos estudos da economia atlântica no século XVIII. 2. ed. São Paulo: Companhia Editora Nacional, 1979.

REDE, Marcelo. História e cultura material. In: CARDOSO, Ciro Flamarion; VAINFAS, Ronaldo (orgs.). Novos domínios da bistória. Rio de Janeiro: Campus, 2012. p. 133-150.

ROBERTS, Lissa. The circulation of knowledge in early modern Europe: embodiment, mobility, learning and knowing. In: INKSTER, Ian (ed.). History of technology. London: Bloomsbury Academic, 2012. vol. 31, p. 47-68.

RUSSELL-WOOD, Anthony John R. Um mundo em movimento: os portugueses na África, Ásia e América (1415-1808). Tradução: Vanda Anastácio. Porto: Difel, 1998.

SANTOS, Joaquim Felício dos. Memórias do Distrito Diamantino. 4. ed. Belo Horizonte: Itatiaia; São Paulo: Edusp, 1976.

SANTOS, Maria José Ferreira dos. Marcas de água e história do papel: a convergência de um estudo. Cultura: Revista de História e Teoria das Ideias, Lisboa, v. 33, p. 11-29, 2014.

SILVA, Flávio Marcus da. Subsistência e poder: a política do abastecimento alimentar nas Minas setecentistas. Belo Horizonte: Editora UFMG, 2008.

ZEMELLA, Mafalda P. O abastecimento da capitania das Minas Gerais no século XVIII. 2. ed. São Paulo: Hucitec, 1990.

Artigo apresentado em 4/4/2020. Aprovado em 1 1/6/2020. (cc) BY 